\title{
A Comparison of Peripheral and Central Axotomy Effects on Neurofilament and Tubulin Gene Expression in Rat Dorsal Root Ganglion Neurons
}

\author{
Johnson Wong and Monica M. Oblinger \\ Department of Cell Biology and Anatomy, Chicago Medical School, North Chicago, Illinois 60064
}

The expression of major cytoskeletal protein mRNAs was studied in adult rat dorsal root ganglion (DRG) neurons after crushing either their central or peripheral branch axons. mRNA levels in DRG neurons were examined by quantitative in situ hybridization with radiolabeled CDNA probes specific for the low-molecular-weight neurofilament protein (NF-L) and $\beta$-tubulin. The large-sized ( $>1000 \mu \mathrm{m}^{2}$ ) neurons which give rise to myelinated axons in lumbar ganglia (L4 and L5) were studied $1 \mathrm{~d}$ through 8 weeks after either dorsal root or sciatic nerve crush. NF-L and $\beta$-tubulin mRNA levels in axotomized DRG neurons were compared to those in contralateral control DRG neurons, as well as to those in normal (completely untreated) DRG cells. In the case of NF-L mRNA, changes were observed after central as well as peripheral branch axotomy and the time course and magnitude of changes were similar after both types of axotomy. NF-L mRNA levels initially decreased (first 2 weeks after crush) and then began to return towards control levels at longer survival times. Similar, but less pronounced, changes in NF-L mRNA levels also occurred in contralateral DRG neurons (which were uninjured); the changes in contralateral neurons were not simply a result of surgical stress since no changes in NF-L mRNA levels were observed in sham-operated DRG neurons. In the case of tubulin mRNA, changes were observed after central as well as peripheral branch axotomy by in situ hybridization, but the time course and magnitude of changes were different after each type of axotomy. $\beta$-Tubulin mRNA levels initially increased (first 2 weeks after axotomy) in DRG neurons after either type of axotomy; however, the magnitude and duration of the increase were less after central than after peripheral branch crush. Also, while tubulin mRNA levels in DRG cells eventually recovered following peripheral axotomy, the levels dropped and remained substantially below control values 48 weeks after dorsal root crush. No changes in tubulin mRNA levels were observed in sham-operated neurons. The results of these studies indicate that a robust cytoskeletal gene response occurs in DRG cells after central as well as after peripheral branch axotomy and demonstrate that the DRG cell recognizes a signal induced by dorsal root axotomy and is capable of mounting a specific molecular response.

\footnotetext{
Received Oct. 30, 1989; revised Dec. 26, 1989; accepted Feb. 2, 1990.

We gratefully acknowledge the excellent technical help of Ben Sanchez and Ron Lang Zheng in these studies and thank Kathryn Jones for her critical comments on this paper. This work was supported by NIH Grant NS-21571 to M.M.O.

Correspondence should be addressed to Dr. Monica M. Oblinger, Department of Cell Biology and Anatomy, Chicago Medical School, 3333 Green Bay Rd., North Chicago, IL 60064.

Copyright (C 1990 Society for Neuroscience $0270-6474 / 90 / 072215-08 \$ 03.00 / 0$
}

It is widely believed that gene expression in a neuron can be influenced by the disposition of the end of its axon. For cytoskeletal genes, compelling support for this idea has come from axotomy studies. For example, within a week or two of crushing or transecting a peripheral nerve, the levels of neurofilament (NF) protein mRNAs in the axotomized neurons decrease (Hoffman et al., 1987; Wong and Oblinger, 1987; Goldstcin ct al., 1988), while those of tubulin increase (Hoffman and Cleveland, 1988; Koo et al., 1988; Pearson et al., 1988; Miller et al., 1989; Oblinger et al., 1989). During a similar initial interval after axonal disconnection, the synthesis and transport of NF and tubulin proteins change in a manner consistent with the changes in mRNA levels (Hoffman and Lasek, 1980; McQuarrie, 1983; Oblinger and Lasek, 1985, 1988; Greenberg and Lasek, 1988; Oblinger et al., 1989). Conditioning lesion studies have suggested that this altered program of cytoskeletal gene expression facilitates regeneration by promoting a faster rate of axon elongation (Oblinger and Lasek, 1984; Oblinger et al., 1989). Presumably, a return to steady-state levels of NF and tubulin gene expression occurs when the regenerating neuron completes its active phase of axon elongation and establishes a new axonal ending in relation to an appropriate target. In support of this idea, recent studies have shown that cytoskeletal protcin synthesis (Greenburg and Lasek, 1988) and NF mRNA levels (Hoffman et al., 1987) return to normal at longer intervals after nerve crush when axonal regeneration has been completed. These findings have led to the hypothesis that cytoskeletal gene expression is modulated by interactions between neurons and their targets via materials that are retrogradely transported to the neuronal cell body from the axon tip (Hoffman et al., 1987; Greenburg and Lasek, 1988).

The dorsal root ganglion (DRG) neuron provides a unique system in which to study the effects of removing the axon terminal on cytoskeletal gene expression because these cells normally maintain 2 different axons that end in relation to very different target cells. The stem axon of adult DRG neurons bifurcates into a central and a peripheral axonal branch. Peripheral branch DRG axons course through peripheral nerves and end in a number of specialized configurations that serve as sensory receptors in various tissues (such as neuromuscular spindle organs, Golgi tendon organs, free nerve endings in skin, various encapsulated endings in skin, etc.). Central branch DRG axons course through the dorsal root and ultimately end as synaptic terminals on neurons in the CNS. Because of this arrangement, axotomy of the central branch would deprive the DRG cell of a different set of target-defined interactions than would peripheral axotomy. Also, while peripheral branch DRG 
axons regenerate efficiently and reestablish normal axon-target cell interactions after crush axotomy, central branch DRG axons do not. Central branch axons do sprout and elongate through the dorsal root after crush axotomy (Oblinger and Lasek, 1984), but they stop growing when they reach the spinal cord entry zone and, thus, do not reestablish connections with their original CNS target neurons (Bignami et al., 1984; Liuzzi and Lasek, 1987). However, it is of interest that regenerating central branch axons often end as structures resembling presynaptic terminals on astroglia at the CNS-dorsal root junction (Liuzzi and Lasek, 1987). Since such abnormal axoglial endings are devoid of NFs and microtubules, it has been suggested that they serve some of the functions of normal axonal endings (Liuzzi and Lasek, 1987).

Some controversy exists over the question of whether removal of the central branch axon affects DRG cell metabolism in the same manner as does peripheral branch axotomy. Studies of DRG neurons from different species documented major morphological changes in the DRG cell body (chromatolysis) after peripheral axotomy that were largely absent after central axotomy (Carmel and Stein, 1969; Cragg, 1970; Lieberman, 1971). Biochemical studies have been both negative (Perry and Wilson, 1981; Hall, 1982; Oblinger and Lasek, 1988) and affirmative (Greenburg and Lasek, 1988) on the question of whether cytoskeletal protein synthesis and/or axonal transport is altered in DRG neurons after dorsal root lesions. At present, no information is available about the DRG cell response to central axotomy at the mRNA level. Do changes in NF and tubulin mRNA levels occur in DRG cells after central axotomy, and, if so, is the time course and magnitude of change different from the peripheral axotomy response? If a response to central crush does occur at the mRNA level, does it recover in spite of permanent disconnection of central axons with their original targets? The present study addressed these questions using quantitative in situ hybridization of rat DRG neurons with NF and tubulin cDNA probes.

\section{Materials and Methods}

Animals. Adult male Sprague-Dawley rats (Harlan Sprague Dawley, Indianapolis, IN) weighing 300-350 gm were used for all experiments. All animals were acquired, cared for, and surgically handled in accordance with the guidelines specified in the NIH Guide for the Care and Use of Laboratory Animals. For surgical procedures, animals were anesthetized with a mixture of sodium pentobarbital $(27 \mathrm{mg} / \mathrm{kg})$ and chloral hydrate $(128 \mathrm{mg} / \mathrm{kg})$; for scheduled kills, animals were decapitated under ether anesthesia.

Unilateral nerve crushes of either the sciatic nerve at $50-55 \mathrm{~mm}$ from the fifth lumbar (L5) DRG (peripheral axotomy site) or the L5 dorsal root at 5-8 $\mathrm{mm}$ from the DRG (central axotomy site) were made as described previously (Oblinger and Lasek, 1984, 1988). At 1, 5-7, 14, 28 , and 5,6 d after axotomy, rats were overdosed with ether, and the experimental (axotomized) and contralateral control L5 DRGs were removed. For each time point and condition in the axotomy experiments, 2-9 rats were prepared and used for in situ hybridization studies. In addition, L5 DRGs from 4 normal rats were harvested and used as normal (untreated) controls and 3 additional rats provided $14 \mathrm{~d}$ shamoperated DRGs for the in situ studies. For the sham surgeries, the right sciatic nerve was surgically exposed (but not crushed), the incision was sutured, and the rats allowed to survive $14 \mathrm{~d}$ after the sham surgery, at which point the L5 ganglia were harvested.

In situ hybridization. Ganglia were fixed by immersion in $4 \%$ paraformaldehyde for 1-3 hr, rinsed for $2 \mathrm{hr}$ in PBS, dehydrated in graded ethanols, and embedded in paraffin. The ganglia were sectioned at 10 $\mu \mathrm{m}$, mounted on chrome-alum gelatin-coated slides stored at $-20^{\circ} \mathrm{C}$ until used for hybridization. In situ hybridization of the sections with ${ }^{35} \mathrm{~S}$-labeled cDNA probes was done as described previously (Wong and Oblinger, 1987). The probes included a cDNA specific for NF-L mRNA

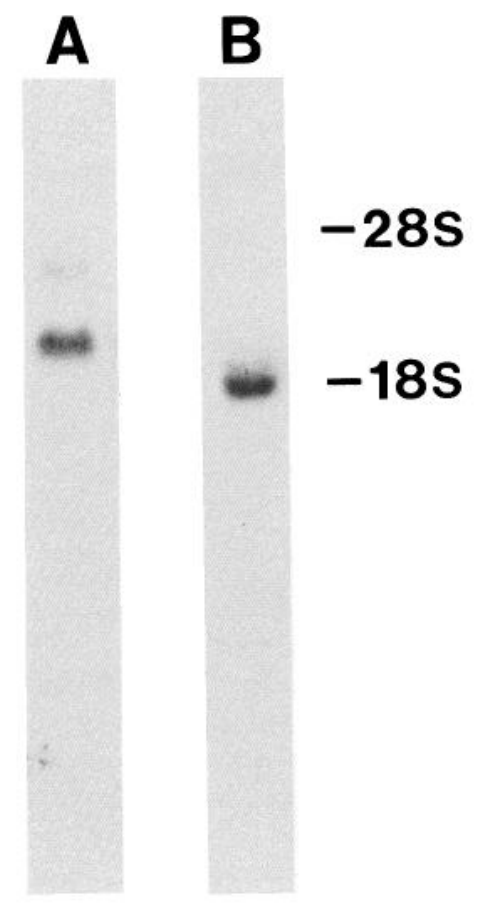

Figure 1. Autoradiogram of an RNA blot illustrating the hybridization of NF-L and tubulin cDNA probes to specific mRNA species in the DRG. The NF-L probe $(A)$ recognized a 4.0 and a 2.5 mRNA species, and the tubulin probe $(B)$ recognized a $1.8 \mathrm{~kb}$ mRNA species. In these blots, $10 \mu \mathrm{g}$ /lane of total RNA isolated from normal DRGs was run on a $1 \%$ agarose gel, transferred to Nytran membranes, and hybridized with ${ }^{32} \mathrm{P}$-labeled cDNA probes. The autoradiograph was exposed for $2 \mathrm{~d}$ with an intensifying screen at $-70^{\circ} \mathrm{C}$. The positions of the ribosomal markers are indicated on the right side of the figure.

(Lewis and Cowan, 1985) and a cDNA for a $\beta$-tubulin mRNA (RBT.1; Bond et al., 1984). After hybridization, the sections were washed to a final stringency of $0.5 \times$ standard saline citrate $(\mathrm{SSC})$ at $24^{\circ} \mathrm{C}$, dehydrated through an increasing series of ethanols $/ 300 \mathrm{~mm}$ ammonium acetate, pH 5.5, dried, dipped into $37^{\circ} \mathrm{C}$ Kodak NTB2 emulsion (diluted 1:1 with $600 \mathrm{~mm}$ ammonium acetate), and stored at $4^{\circ} \mathrm{C}$ in the dark for $2-$ $7 \mathrm{~d}$. After development, the sections were lightly stained with cresyl violet, coverslipped with Permount, and examined under the light microscope.

The autoradiograms were quantitatively evaluated by determining the density of silver grains over DRG neurons in which a clearly defined nucleus and nucleolus were present using a computer-based image analysis system as described previously (Wong and Oblinger, 1987). Measurements of nonspecific background labeling were made from each section by determining the grain density over axonal regions of the DRG (that did not contain neuronal cell bodies); the grain counts over neurons from any given section were corrected for nonspecific labeling. Only large-sized DRG neurons, defined as those cells having a cross-sectional area of $>1000 \mu \mathrm{m}^{2}$ were examined. From each ganglion, grain counts from 25-40 neurons were obtained and mean grain density values were determined by averaging. Data for each of the experimental conditions were expressed as mean ratios of the grain density values of experimental versus control neurons. Both contralateral controls and normal untreated controls were used to evaluate the experimental effect at each postaxotomy time point.

RNA blots. Total RNA was isolated from normal DRGs as described (Chomcyznski and Sacchi, 1987). RNA (10 $\mu \mathrm{g} / \mathrm{gel}$ lane) was separated by electrophoresis on $1 \%$ agarose gels in the presence of formaldehyde (Ausubel et al., 1987) and blotted onto Nytran membranes (Schleicher and Schuell). The blots were hybridized with ${ }^{32} \mathrm{P}$-labeled cDNA probes to NF-L and $\beta$-tubulin as described (Ausubel et al., 1987) and washed to a final stringency of $0.5 \times \mathrm{SSC}$ with $0.1 \%$ SDS at $25^{\circ} \mathrm{C}$. Autoradiographs were made by exposing Kodak XAR5 film to the blots for 1-2 d. The autoradiographs were used to confirm that each of the cDNA 

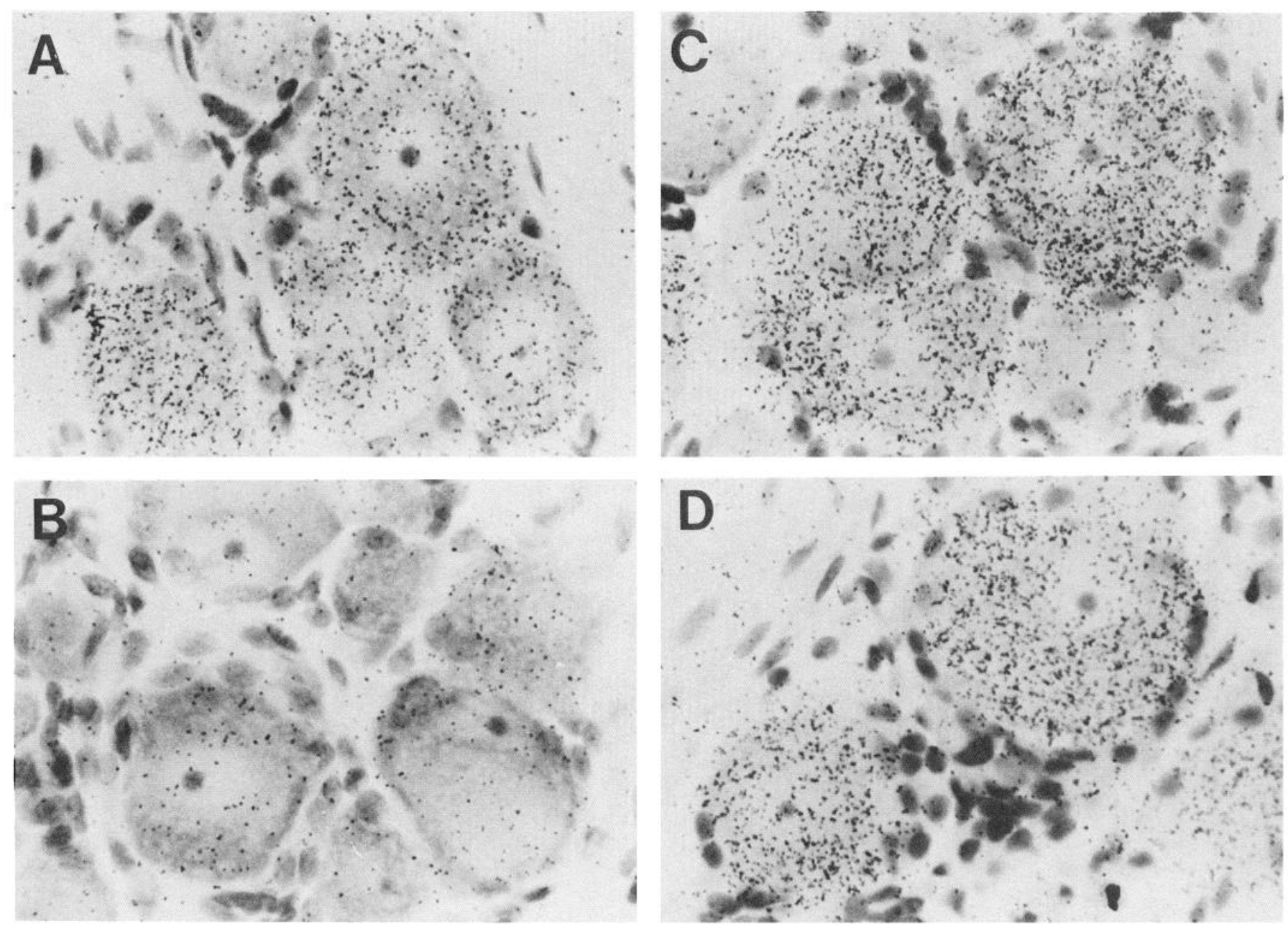

Figure 2. Autoradiograms of DRG cells hybridized in situ with a ${ }^{35}$ S-labeled cDNA probe to NF-L. $A$, Contralateral control DRG cells at 14 d; $B$, axotomized DRG cells $14 \mathrm{~d}$ after central branch crush; $C$, contralateral control neurons at $56 \mathrm{~d} ; D$, axotomized DRG cells $56 \mathrm{~d}$ after central branch crush.

probes hybridized to specific and unique mRNA species in the DRG. The NF-L probe recognized a 4.0 and a 2.5 mRNA species and the tubulin probe recognized a $1.8 \mathrm{~kb}$ mRNA species in the DRG (Fig. 1).

\section{Results}

Effects of central versus peripheral axotomy on NF-L mRNA levels in DRG cells

In situ hybridizations of histological sections of DRG neurons with a ${ }^{35} \mathrm{~S}$-labeled cDNA probe were done to compare the effect of dorsal root crush with that of sciatic nerve crush on NF-L mRNA levels 1-56 d after axotomy. Visual comparisons of autoradiograms revealed that central and peripheral axotomy produced similar patterns of change in NF-L mRNA levels. These changes included a progressive reduction in the labeling of axotomized neurons during the first 2 weeks after axotomy followed by recovery towards normal levels of labeling at longer times after the crush (examples at 2 and 8 weeks after dorsal root crush are shown in Fig. 2). Qualitatively, the autoradiograms obtained after sciatic nerve crush (examples not shown) were indistinguishable from those obtained after dorsal root crush.

Autoradiograms were quantitatively evaluated using a computer-based image analysis system to assess the magnitude of changes in NF-L mRNA levels that occurred after central and peripheral branch axotomy. The mean grain densities of largesized $\left(>1000 \mu \mathrm{m}^{2}\right)$ DRG neurons were determined at different times after dorsal root or sciatic nerve crush. Two different types of controls, contralateral ganglia at each time point and normal (untreated) ganglia, were examined and the data expressed as ratios (experimental: contralateral control and experimental: normal control; Fig. 3). This analysis confirmed that the changes in NF-L mRNA levels resulting after central axotomy (Fig. 3A) were quite similar to those that occurred after peripheral axotomy (Fig. $3 B$ ). After either type of axotomy, NF-L mRNA levels in large neurons decreased during the first 2 weeks and then increased towards control levels during weeks $4-8$ after nerve crush.

An interesting finding was that the relative magnitude of reduction in NF-L mRNA levels in axotomized DRG neurons was more pronounced when experimental neurons were compared to normal, untreated controls rather than to contralateral control neurons (Fig. 3). For example, the NF-L mRNA level in axotomized neurons $14 \mathrm{~d}$ after peripheral crush was about $35 \%$ of that in normal DRG cells but only $63 \%$ that in paired contralateral control DRG neurons (Fig. $3 B$ ). This difference was due to a reduction in the labeling of the contralateral control 


\section{A. Central axotomy}

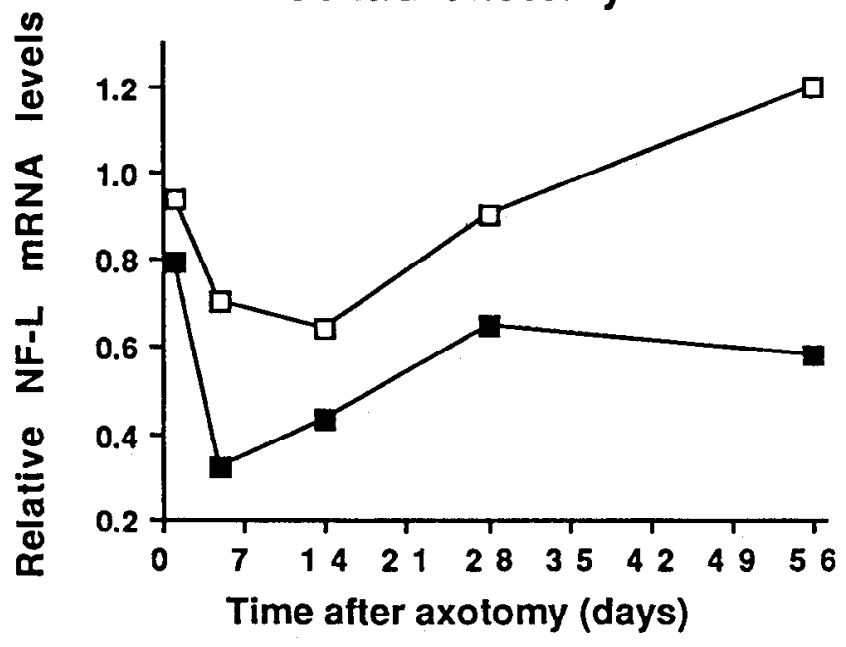

B. Peripheral axotomy

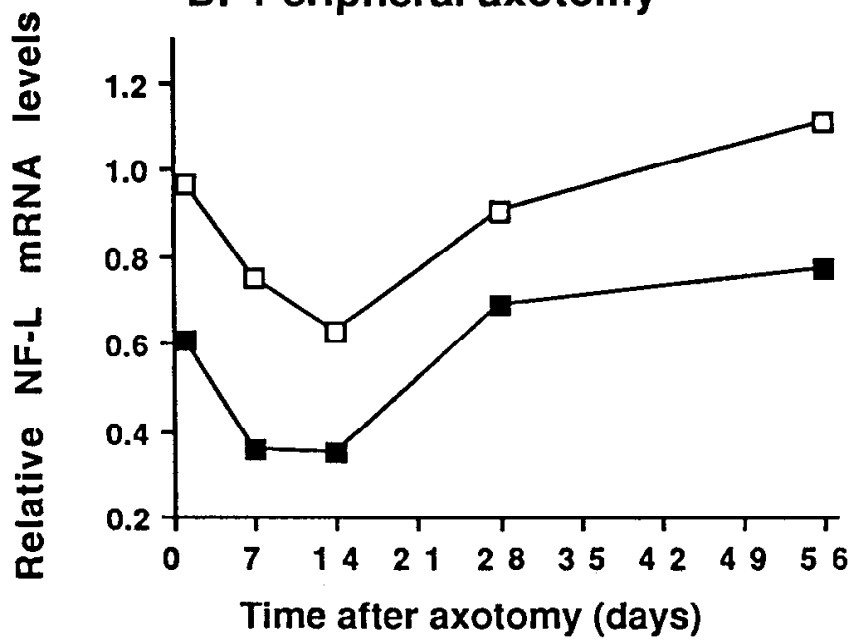

Figure 3. Quantitation of changes in the level of NF-L mRNA in large DRG neurons as a function of time after $(A)$ central branch axotomy (dorsal root crush) and $(B)$ peripheral branch axotomy (sciatic nerve crush). Mean grain densities (number of silver grains $/ \mu \mathrm{m}^{2}$ of cell area) of axotomized and control DRG neurons were determined and expressed as ratios of experimental to control values. Data obtained using 2 different types of controls, contralateral DRGs (open squares) and normal DRGs (closed squares), are presented. Each ratio plotted incorporates mean data from 2-9 ganglia (from each of which 25-40 large cells were counted) per condition.

neurons relative to normal neurons and was observed in both the peripheral crush and dorsal root crush experiments. To determine whether the changes in contralateral DRG neurons were due to some nonspecific effect of surgery, 3 sham-operated animals prepared at the $14 \mathrm{~d}$ time point were examined. The ratio of grain densities from the NF-L in situ experiments in the shamoperated, large-sized DRG neurons to the normal controls was 0.9 , indicating that sham surgery had no effect on NF-L mRNA levels. This suggested that the contralateral changes in the crush axotomy experiments were not simply a consequence of surgical stress.
Effects of central versus peripheral axotomy on $\beta$-tubulin $m R N A$ levels in DRG cells

In situ hybridization of DRG neurons was used to examine $\beta$-tubulin mRNA levels $1-56 \mathrm{~d}$ after central and peripheral axotomy. Qualitative evaluation of autoradiograms of DRG neurons hybridized with the tubulin cDNA probe revealed increases in the labeling of large-sized DRG cells in the initial weeks after axotomy and decreases towards or below control levels at later times. The increase in tubulin mRNA levels at early times after axotomy was observed after both central branch crush (Fig. 4) and peripheral branch crush (not shown). At longer intervals after axotomy, an interesting difference between the 2 axotomy conditions was apparent in the autoradiographs of DRG cells. The labeling of centrally axotomized DRG neurons was reduced well below control levels at 8 weeks after nerve crush (Fig. 4). However, at this time after peripheral axotomy, the labeling of large DRG neurons had returned to control levels (example not shown).

Quantitative analysis largely confirmed the qualitative observations concerning changes in $\beta$-tubulin mRNA levels. The ratios of grain densities (experimental to control values) in largesized DRG neurons indicated increases at $14 \mathrm{~d}$ after dorsal root crush (Fig. 5A) and at 7 and $14 \mathrm{~d}$ after sciatic nerve crush (Fig. $5 B$ ). The labeling of experimental neurons was nearly twice that of contralateral controls $14 \mathrm{~d}$ after peripheral axotomy (Fig. $5 B$ ); the increase observed at that time point after central axotomy was slightly less than this (Fig. 5A). At long postcrush intervals ( 8 weeks), the tubulin mRNA level had returned to normal in peripherally axotomized DRG cells (Fig. $5 B$ ) but had dropped to about half the control level in centrally axotomized neurons (Fig. 5A).

The pattern of changes in tubulin mRNA levels after central axotomy were very similar when experimental neurons were compared to either contralateral controls or normal controls (Fig. 5). These patterns were also similar in the peripheral crush condition (Fig. $5 B$ ). To assess sham surgery effects in the experiments, large-sized DRG neurons from 3 sham-operated animals were quantitatively evaluated using in situ hybridization with the tubulin cDNA probe. The ratio of grain densities in the $14 \mathrm{~d}$ sham-operated DRG neurons to normal control neurons was 0.9 , indicating that there was no sham effect on tubulin mRNA levels in large-sized DRG neurons.

\section{Discussion}

The present study demonstrates that DRG neurons respond to disconnection of their central axons. The most robust component of this response is a decrease in the levels of NF-L mRNA and an increase in $\beta$-tubulin mRNA levels during the initial weeks after axotomy. To our knowledge, this is the first information available about changes in $M R N A$ levels in mammalian DRG cells in response to dorsal root axotomy. A recent study that compared the synthesis of NF and tubulin in DRG after central and peripheral axotomy reported significant changes in $\mathrm{NF}$ but not tubulin synthesis beginning $5 \mathrm{~d}$ after dorsal root crush (Greenburg and Lasek, 1988). Our present findings extend those observations about the cytoskeletal response in centrally axotomized DRG cells to the mRNA level. Thus, while considerable controversy has existed in the past over the question of whether DRG neurons undergo any response to central branch axotomy (reviewed in Cragg, 1970; Lieberman, 1971), it is now 

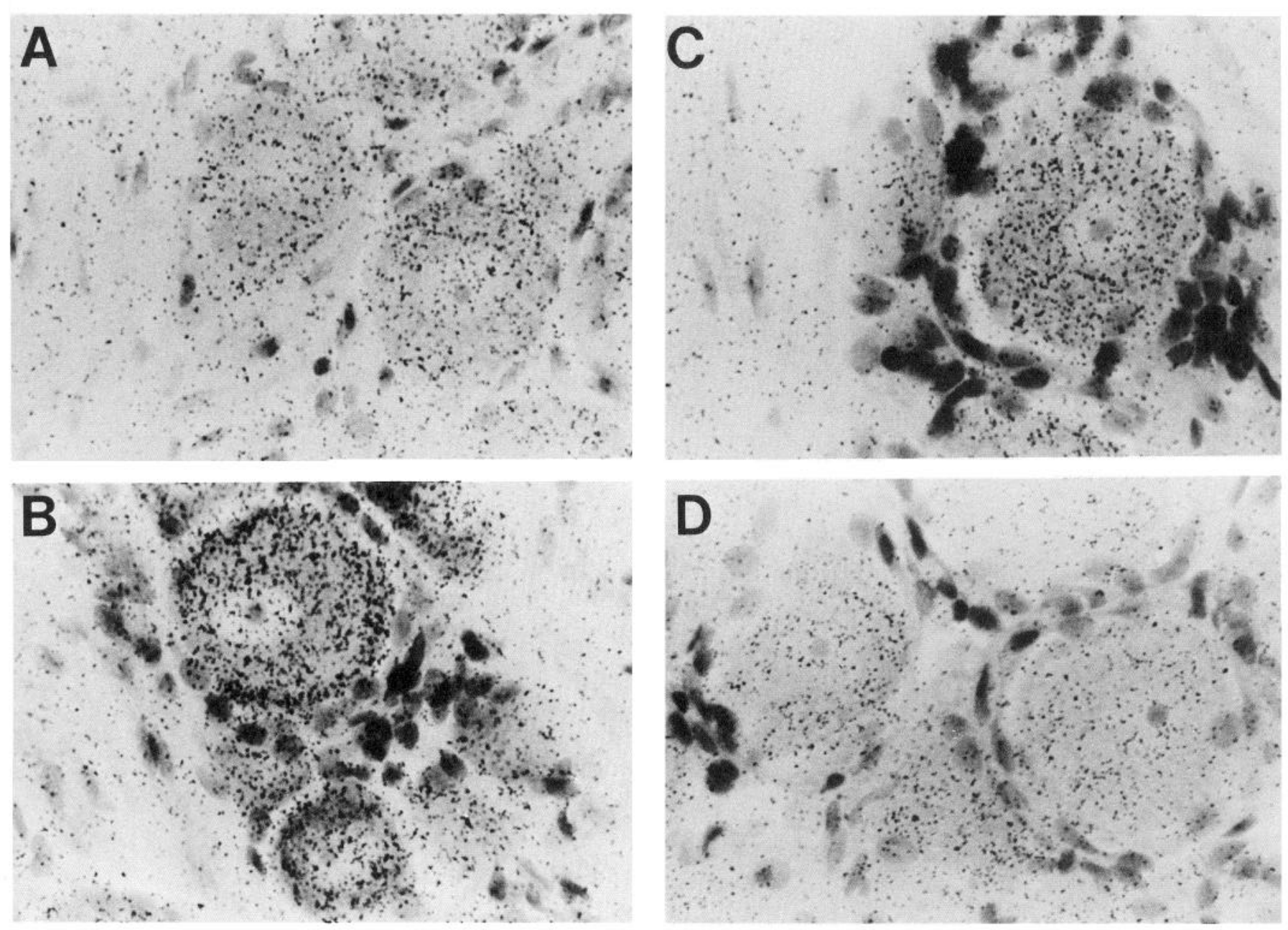

Figure 4. Autoradiograms of DRG cells hybridized in situ with a ${ }^{35}$ S-labeled cDNA probe to $\beta$-tubulin $A$, Contralateral control DRG cells at 14 d; $B$, axotomized DRG cells $14 \mathrm{~d}$ after central branch crush; $C$, contralateral control neurons at $56 \mathrm{~d} ; D$, axotomized DRG cells $56 \mathrm{~d}$ after central branch crush.

quite clear that DRG cells are capable of mounting a specific molecular response to central axotomy.

The present study also documents differences between the response of DRG cells to central and peripheral axotomy. These include a smaller magnitude and shorter duration of change in NF and tubulin mRNA levels after central crush than after peripheral crush. Central branch axotomy has also been reported to affect cytoskeletal protein synthesis in DRG cells less dramatically than peripheral branch axotomy (Greenberg and Lasek, 1988). A further difference between the 2 axotomy conditions emerges at longer intervals after crush when axonal regeneration is complete in the peripheral crush condition but is not complete (in the sense of axons reaching their original targets) after central axotomy. Specifically, tubulin mRNA levels fall well below control levels in DRG neurons by 8 weeks after dorsal root crush but return to control levels by 8 weeks after sciatic nerve crush. A long-term down-regulation of tubulin mRNA levels has not been reported in any previous study of axotomized mammalian neurons.

It is commonly assumed that the time course and magnitude of change in the expression of cytoskeletal genes must somehow be related to the progress of axonal regeneration and the success or failure of axonal reconnection with target cells. The results of the present study provide some support for this idea. For example, the levels of $\beta$-tubulin mRNA are increased during a period of time when DRG axons are actively elongating in response to either central or peripheral axotomy. This increased level of expression could potentially facilitate the regenerative process by up-regulating the overall supply of microtubules or by changing the composition of microtubules by selectively increasing the expression of certain tubulin isotypes. When successful regeneration and reconnection of the axons with normal targets occurs (after peripheral branch crush), tubulin expression returns to normal. In contrast, failure to reconnect with normal targets (in the case of crushed dorsal root axons which do not grow beyond the CNS entry zone) results in a long-term reduction in the level of tubulin gene expression in the DRG neurons. Thus, the disposition of the end of the axon and target interaction may be important factors in determining the level of tubulin gene expression in these neurons.

Identification of the actual factors and the molecular details of regulation of cytoskeletal genes is an important avenue of active research at present. For tubulin genes, it has long been known that the level of tubulin monomer in cells is an important factor that can regulate gene expression (Ben-ze'ev et al., 1979; Cleveland et al., 1981; Lau et al., 1986). As the concentration of monomer in cells decreases, tubulin synthesis as well as mRNA levels increase and vice versa. It is not known whether axotomy 

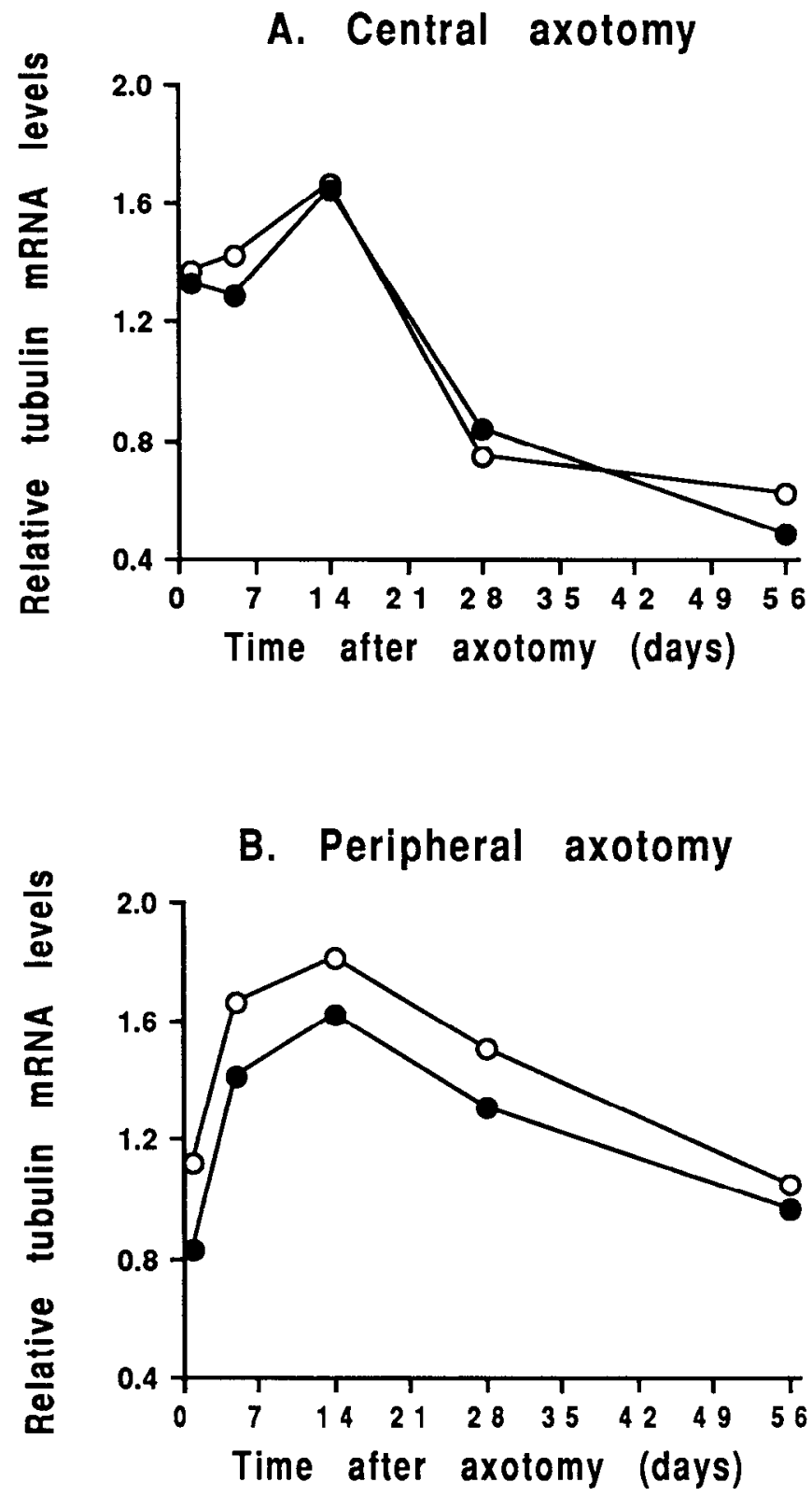

Figure 5. Quantitation of changes in the level of $\beta$-tubulin mRNA in large DRG neurons as a function of time after $(A)$ central branch axotomy (dorsal root crush) and $(B)$ peripheral branch axotomy (sciatic nerve crush). Mean grain densities (number of silver grains $/ \mu \mathrm{m}^{2}$ of cell area) of axotomized and control DRG neurons were determined and expressed as ratios of experimental to control values. Data obtained using 2 different types of controls, contralateral DRGs (open circles) and normal DRGs (closed circles), are presented. Each ratio plotted incorporates mean data from 2-7 ganglia (from each of which 25-40 large cells were counted) per condition.

affects the polymer/monomer ratio for tubulin in neurons. However, because of the long time course of changes in tubulin mRNA levels and the differences between the long-term effects of central and peripheral axotomy, it is likely that other factors are also involved in the regulation of tubulin gene expression in DRG neurons. Recent studies have shown that not all tubulin genes are influenced to the same extent by axotomy (Hoffman and Cleveland, 1988). The expression of the class II $\beta$-tubulin gene is greatly increased after axotomy, while the class I and IV $\beta$-tubulin genes are much less influenced; class III $\beta$-tubulin genes have not yet been evaluated in axotomized neurons. The tubulin cDNA probe used in the present study recognizes predominantly the $1.8 \mathrm{~kb}$ mRNA product of a class II $\beta$-tubulin gene, which is normally expressed at higher levels in the immature brain than in the adult (Bond et al., 1984).

Dorsal root axons do not "successfully regencratc" in the sense of reestablishing functional connections with appropriate target cells. If the simplistic model whereby neuronal cytoskeletal gene expression is regulated by the successful reconnection of axons with target cells were correct, one would predict that cytoskeletal gene expression should not return to normal after dorsal root crush. While this appears to be true for tubulin mRNA levels, it is apparently not true for NF gene expression. Changes in NF mRNA levels had a similar magnitude and time course after both peripheral and central axotomy, and the mRNA levels returned to contralateral control levels after both types of axotomy. While these results could suggest that appropriate target interactions (or target-derived factors) are not as important for the recovery of normal expression of NF genes as they are for the tubulin genes, other possibilities must also be considered. In this regard, it is important to recall that, although central branch DRG axons do not reconnect to their original targets, regenerating dorsal root axons make synaptic-like endings on astrocytes at the CNS entry zone, and it has been proposed that such terminations on astrocytes halt further axon regeneration by providing a functional "stop" signal to the neuron (Lasek and Liuzzi, 1987). In the case of NF genes, it is possible that such signals may act to return the levels of expression lowards normal in spite of the lack of reconnection to appropriate target cells.

The nature of signals/factors generated by or at the end of the axon that can influence gene expression in the neuron cell body is only a matter of speculation at present. Clearly, these signals could be derived from exogeneous sources (target) that are taken up at the axon terminal or from materials within the neuron that are modified at the axon terminal and returned to the cell body by retrograde transport. In light of our findings of NF mRNA changes in DRG, the latter is particularly intriguing. NF proteins are transported by slow axonal transport to the axon terminal, where they are degraded by calcium-activated proteases (Lasek et al., 1983). It is possible that NF degradation products generated at a "functional axon ending" and transported retrogradely back to the cell body are important in regulating NF gene expression. In the case of regenerating dorsal root axons, axoglial endings are "functional" in the limited sense that they apparently can degrade NFs because electron microscopic studies have shown that these aberrant axon endings are devoid of cytoskeletal elements (Liuzzi, and Lasek, 1987). Thus, these endings may function to enable NF mRNA expression to return to control levels after dorsal root crush. Clearly, a different mechanism of regulation is extant for tubulin expression, which does not recover after central axotomy.

A final issue which requires consideration is the observation that molecular changes occur in contralateral DRG neurons. In the present study we observed a robust down-regulation of NF mRNA levels in uninjured neurons located in the contralateral DRG. This was seen in both central and peripheral axotomy conditions with in situ hybridization and has not been previously reported. It is of interest that reductions in fiber diameter in the contralateral sciatic nerve after unilateral nerve crush were carefully documented much earlier this century (Greenman, 1913; Tamaki, 1936). In our current understanding, axon 
caliber is regulated largely by NF number, and a reduction in NF number can be the direct result of down-regulation of NF gene expression (Lasek et al., 1983; Hoffman et al., 1987). Thus, our present results demonstrate the underlying molecular basis for reported changes in axonal caliber of axotomized (Greenman, 1913; Hoffman et al., 1987), as well as contralateral (Greenman, 1913), DRG cell axons.

A number of other changes in contralateral neurons after peripheral nerve injury have been reported (Watson, 1968; Lieberman, 1971; Pearson and Powell, 1986; Pearson et al., 1988). More recently, increased levels of tubulin mRNA have been reported in contralateral (as well as axotomized) hypoglossal and facial nuclear groups after nerve transection (Pearson et al., 1988). Interestingly, our in situ hybridization data did not reveal an increase in tubulin mRNA levels in large-sized DRG neurons contralateral to the axotomy. Why and how do molecular changes occur in neurons that are contralateral to axotomized cells? While we do not have an answer to this question, it is clearly an important issue since, in many axotomy studies, axotomized neurons are compared with corresponding contralateral neurons of the experimental animal. A still reasonable hypothesis for contralateral changes after axotomy is a "work hypertrophy" effect originally proposed by Watson (1968). In such a model, increased work of the contralateral limb to compensate for the denervated limb might result in terminal or preterminal sprouting of sensory fibers to innervate a larger target. For motor fibers, sprouting of uninjured motor fibers on the contralateral side of the animal after axotomy has been well documented (Ring et al., 1983; Rotshenker and Tal, 1985). Similar studies for sensory fibers have not been reported, probably due to technical difficulties in conducting such studies. However, if sprouting does occur in sensory fibers on the contralateral side, the molecular changes observed in these noninjured neurons may simply be a reflection of such limited axonal growth.

In summary, this study has revealed a number of molecular changes that occur in DRG neurons in response to axotomy. The sensitivity of the in situ hybridization method has enabled us to provide definitive evidence that large DRG neurons respond to axotomy of their central branch axons as well as of their peripheral axons. We have demonstrated that NF mRNA levels decrease and that $\beta$-tubulin mRNA levels increase in the initial weeks after central or peripheral branch axotomy. The differences in the direction of change and in the recovery of NF and tubulin mRNA levels after axotomy suggest that major differences exist in the regulation of these 2 types of cytoskeletal genes. The aberrant synapse-like endings known to be made by regencrating dorsal root axons on astroglia (Liuzzi and Lasck, 1987) appear to generate sufficient signals to enable NF gene expression to recover in DRG cells after central axotomy; this does not appear to be true for tubulin gene expression. Interactions between neurons and their targets clearly have important roles in cytoskeletal gene expression, and it will be of great importance to begin defining the molecular signals/factors generated by such interactions that can influence the production and properties of the neuronal cytoskeleton.

\section{References}

Ausubel R, Brent R, Kingston RE, Moore DD, Seidman JG, Smith JA, Struhl K (1987) In: Current protocols in molecular biology, pp 4.9.14.9.5. New York: New Greene Assoc. and Wiley Interscience.

Ben-ze'ev A, Farmer SR, Penman S (1979) Mechanisms regulating tubulin synthesis in cultured mammalian cells. Cell 17:319-325.
Bignami A, Chi NH, Dahl D (1984) Regenerating dorsal roots and the nerve entry zone: an immunofluorescence study with neurofilament and laminin antisera. Exp Neurol 85:426-436.

Bond JF, Robinson GS, Farmer SR (1984) Differential expression of two neural cell specific $\beta$-tubulin mRNAs during rat brain development. Mol Cell Biol 4:1313-1319.

Carmel PW, Stein BM (1969) Cell changes in sensory ganglia following proximal and distal nerve section in the monkey. $\mathrm{J}$ Comp Neurol 135:145-166

Chomcyznski P, Sacchi N (1987) Single-step method of RNA isolation by acid guanidinium thiocynate-phenol-chloroform extraction. Anal Biochem 162:156-159.

Cleveland DW, Lopata MA, Sherline P, Kirschner MW (1981) Unpolymerized tubulin modulates the level of tubulin mRNAs. Cell 25: 537-546.

Cragg BG (1970) What is the signal for chromatolysis? Brain Res 23: $1-21$.

Goldstein ME, Weiss SR, Lazzarini RA, Shneidman PS, Lees JF, Schlaepfer WW (1988) mRNA levels of all three neurofilament proteins decline following nerve transection. Mol Brain Res 3:287292.

Greenberg SG, Lasek RJ (1988) Neurofilament protein synthesis in DRG neurons decreases more after peripheral axotomy than after central axotomy. J Neurosci 8:1739-1746.

Greenman MJ (1913) Studies on the regeneration of the peroneal nerve of the albino rat: number and sectional areas of fibers: area relation of axis to sheath. J Comp Neurol 23:479-513.

Hall, ME (1982) Changes in synthesis of specific proteins in axotomized dorsal root ganglia. Exp Neurol 76:83-93.

Hoffman PN, Cleveland DW (1988) Neurofilament and tubulin expression recapitulates the developmental program during axonal regeneration: induction of a specific $\beta$-tubulin isotype. Proc Natl Acad Sci USA 85:4530-4533.

Hoffman PN, Lasek RJ (1980) Axonal transport of the cytoskeleton in regenerating motor neurons: constancy and change. Brain Res 202: 317-333.

Hoffman PN, Cleveland DW, Griffin JW, Landes PW, Cowan NJ, Price DL (1987) Neurofilament gene expression: a major determinant of axonal caliber. Proc Natl Acad Sci USA 84:3472-3476.

Koo EH, Hoffman PN, Price DL (1988) Levels of neurotransmitter and cytoskeletal protein mRNAs during nerve regeneration in sympathetic ganglia. Brain Res 449:361-363.

I asek RJ, Oblinger MM, Drake PF (1983) Molecular biology of neuronal geometry: expression of neurofilament genes influences axonal diameter. Cold Spring Harbor Symp Quant Biol 48:731-743.

Lau JTY, Pittenger MF, Havercroft JC, Cleveland DW (1986) Reconstruction of tubulin gene regulation in cultured mammalian cells. Ann NY Acad Sci 466:75-88.

Lewis SA, Cowan NJ (1985) Genetics, evolution and expression of the 68,000-mol-wt neurofilament protein: isolation of a cloned cDNA probe. J Cell Biol 100:843-850.

Lieberman AR (1971) The axon reaction: a review of the principal features of perikaryal responses to axon injury. Int Rev Neurobiol 14:49-124.

Liuzzi FJ, Lasek RJ (1987) Astrocytes block axonal regeneration in mammals by activating the physiological stop pathway. Science 237 : 642-645.

McQuarrie IG (1983) Role of the axonal cytoskeleton in the regenerating nervous sytem. In: Nerve, organ and tissue regeneration: research perspectives (Seil FJ, ed), pp 51-86. New York: $\Lambda$ cademic.

Miller FD, TetzlaffW, Bisby MA, Fawcett JW, Milner RJ (1989) Rapid induction of the major embryonic $\alpha$-tubulin mRNA, T $\alpha 1$, during nerve regeneration in adult rats. J Neurosci 9:1452-1463.

Oblinger MM, Lasek RJ (1984) A conditioning lesion of the peripheral axons of dorsal root ganglion cells accelerates regeneration of only their peripheral axons. J Neurosci 4:1736-1744.

Oblinger MM, Lasek RJ (1985) Selective regulation of two axonal cytoskeletal networks in dorsal root ganglion cells. In: Neurobiology: molecular biological approaches to understanding neuronal function and development (Lague PO, ed), pp 135-143. New York: Liss.

Oblinger MM, Lasek RJ (1988) Axotomy-induced alterations in the synthesis and transport of neurofilaments and microtubules in dorsal root ganglion cells. J Neurosci 8:1747-1758.

Oblinger MM, Szumlas RA, Wong J, Liuzzi FJ (1989) Changes in cytoskeletal gene expression affect the composition of regenerating 
axonal sprouts elaborated by dorsal root ganglion neurons in vivo. J Neurosci 9:2645-2653.

Pearson RCA, Powell TPS (1986) Hypertrophy of motor neurons in the oculomotor nucleus of the rat following removal of the contralateral extraocular muscles. Brain Res 382:184-192.

Pearson RCA, Taylor N, Snyder SH (1988) Tubulin messenger RNA: in situ hybridization reveals bilateral increases in hypoglossal and facial nuclei following nerve transection. Brain Res 463:245-249.

Perry GW, Wilson DL (1981) Protein synthesis and axonal transport during nerve regeneration. J Ncurochem 37:1203-1217.

Ring, G, Reichert F, Rotshenker S (1983) Sprouting in intact sartorius muscles of the frog following contralateral axotomy. Brain Res 260: 313-316.
Rotshenker S, Tal M (1985) The transneuronal induction of sprouting and synapse formation in intact mouse muscles. J Physiol (Lond) 360 : 387-396.

Tamaki K (1936) Further studies on the effect of section of one peroneal nerve of the albino rat on the intact nerve of the opposite side. $J$ Comp Neurol 64:437-448.

Watson WE (1968) Observations on the nucleolar and total cell body nucleic acid of injured nerve cells. J Physiol (Lond) 196:655-676.

Wong J, Oblinger MM (1987) Changes in neurofilament gene expression occur after axotomy of dorsal root ganglion neurons: an in situ hybridization study. Metab Brain Dis 2:291-303. 